\title{
Bernstein's Code Theory and the Educational Researcher
}

\author{
Leanne Cause \\ Faculty of Arts and Education, Deakin University \\ Burwood Hwy, Burwood, Australia \\ Tel: 439-769-768 E-mail: cause.leanne.a@edumail.vic.gov.au
}

\begin{abstract}
This paper explores the applicability of Bernstein's most recent development of his code theory to educational research. It is argued that by using his code theory as a theoretical framework of a project, one can provide a language of description from which to make explicit the ways in which knowledge is relayed through the curriculum, assessment and pedagogy within an educational organization. Although complex, for the educational researcher that is brave enough to invest the energy and time necessary to understand his work, his literature and empirical research provides a unique and very convincing way of viewing the ways in which society reproduces difference and social status through the relationships of the distribution of power, class relations, communication codes (restricted and elaborated) and the principals of control (1975, 1990, 2000; Dickinson \& Erben, 1995).
\end{abstract}

Keywords: Bernstein, Educational research, Classification and framing

\section{An introduction to Bernstein}

\subsection{Introduction}

Fundamentally, Bernstein's most recent development of his code theory examined the general principles underlying the transformation of knowledge into pedagogic communication (Bernstein, 2000). His theory, which was developed over a period of more than 30 years, took into account the actual relay of pedagogic communication - not solely the ideology behind pedagogical messages and their institutional, organizational and philosophical base. In fact, he argued that ideology was constructed through the nature of the relay (or transmission). Researchers all too often avoid using his theory as a theoretical foundation to their project due to the complexity of his work, yet for researchers exploring educational issues; his theory can work very well.

This paper will discuss how by using his code theory as a theoretical framework of a project, one can provide a language of description from which to make explicit the ways in which curriculum, assessment and pedagogy within an educational organization is relayed and ways in which this can work to construct and determine what is to be learnt, how content is to be learnt and when certain subject content are learnt. It is the nature of the relay that makes learning possible, yet it often receives too little attention in educational research.

\subsection{Bernstein's code theory, and critics}

Bernstein's code theory does not lend itself towards providing an adequate, straight forward description as 'his ideas do not translate easily into simple formulae. They demand serious attention' (Atkinson, 2001, p. 37). This could be one of the very reasons as to why many researchers avoid using his theory as a theoretical foundation to a project. King $(1976,1981)$ critiques his concepts on the grounds of theoretical and empirical evidence. However, in several of his publications he has closely associated accounts of research that he was involved in that used his theory as the theoretical foundation. In these circumstances, the concepts of his theory provided clear descriptions and allowed interpretation. (see Bernstein, 1971; 2000 part II)

Pring (1975) criticized Bernstein's theory as he questioned the structure of his theory, stating that his categories are simple dichotomies - though anyone who views his work as simple dichotomies rather than conflicting forms is overlooking the range of realizations that his concepts cover. Gibson (1977) questioned the whole applicability of his theory, claiming that it was far too ambiguous to the point that it's operational levels fail and Walford (1994) agreed. He stated that Bernstein's development of his earlier theories (Bernstein, 1990) are:

'...virtually unreadable, and the complexity is such that the original illuminative nature of the concepts has been obscured. The opacity of Bernstein's writing is also partly responsible for the continued criticism to which it has been subjected. In fact, since the original formulation, criticisms appear to have been more plentiful than examples of use'. (p. 118) 
Walford was correct in the sense that his theory indeed is complex and at times appears unreadable. However, for the educational researcher that are brave enough to invest the energy and time necessary to understand his work, his literature and empirical research provides a unique and very convincing way of viewing the ways in which society reproduces difference and social status through the relationships of the distribution of power, class relations, communication codes (restricted and elaborated) and the principals of control (1975, 1990, 2000; Dickinson \& Erben, 1995). For the purpose of many educational research projects that explore teaching, learning, or curriculum issues, his theory has the potential to provide a language in which to describe the ways in which teachers relay information in the classroom. Bernstein's concepts of his code theory can provide an exceptional and specialized description that many other theories fail to embellish on.

In summary, although highly criticised but at the same time highly respected, his work analyzed the relationships between the processes of schooling and social class reproduction, public language, shared meanings and authority and communication codes, practice and pedagogic discourse (Sadovnik, 2001). With the concept of code at the centre, he produced quite a complex theory on the effects of educational and social codes on social class reproduction.

\subsection{Bernstein's Predecessors}

Bernstein's work was most largely influenced by Emile Durkeim, but not entirely as such a claim would undervalue the potential of his contribution to the field of education and would convey a homogenous view of his work, constraining the possibilities of his theories. Although his work was '...structuralist in its approach, Bernstein's sociology has drawn on the essential theoretical orientations in the field - Durkheimian, Weberian, Marxist and interactionist - and provides the possibility of an important synthesis'. (Sadovnik, 2001, p. 12) This is why it is dangerous to categorize Bernstein's theories within a particular theoretical framework. His theories cannot be viewed as belonging to a categorical box named 'structuralism' or 'positivism' with strong boundaries - the concepts from his theories need to be viewed as more flexible than this as often they have a functionalist nature to them. (Wilkes, 1990) For this reason, it is more appropriate to discuss his main predecessors rather than categorize his work in one particular sociological category.

Although most heavily influenced by Durkheim, many themes of Pierre Bourdieu and Michael Foucault run through Bernstein's work. For example, like Bourdieu and Foucault, Bernstein was concerned with the principles of cultural and social reproduction and the contexts, conditions and environments which form or influence these. Bourdieu's $(1973,1974,1979,1991)$ theory on the reproduction of difference proposed that the culture of the school is set by the dominant culture or class in society and as such, he referred to the educational system as an 'institutional classifier'. He portrayed the cultural classes within the culture of the school as basically 'mirroring' the classes within broader society. In schools, he claimed that agents (students) struggle for capital - credentials or values and styles of the dominant class in society. He stated that it is this 'mirroring' that reproduces the dominant group in society:

'Bourdieu has argued that it is the culture of the dominant group (the group (or groups) that controls the economic, social and political resources) which is embodied in the schools, and that it is this 'embodiment' that works as a reproduction strategy for the dominant group. Such a reproduction strategy is never complete or perfect, but is an element of the process of class reproduction...' (Wilkes, 1990, p. 87)

Just as society favors groups, institutions and individuals with economic capital, so do schools favor the dominant cultural group within that organization, hence the notion of social capital arises:

'He (Bourdieu) asks us to think of cultural capital in the same way we think of economic capital...Just as our dominant economic institutions are structured to favor those who already possess economic capital, so our educational institutions are structured to favor those who already possess cultural capital, in the form of the habitus of the dominant cultural fraction. The schools, he argues, take the habitus of the dominant group as the natural and only proper sort of habitus and treat all children as if they had equal access to it'. (Harker, 1990, p. 86)

One of the main differences between Bernstein and Bourdieu can be seen in the degree of influence that Durkeim had on Bernstein's work. Dickinson and Erben (1995) state that Marx and Mead also inspired much of Bernstein's work, although it was not as palpable as the influence that Durkheim had on his most recent work. Jenks (1995) claimed that Bernstein's theories drew mainly from Durkheim's analysis of complex and simple forms of social organization when describing the organization of schools and the influences this has on the individual and personal identity of the child. Where Mead left gaps in her theory on the ways in which society constructs different social roles and transforms individual identity, Bernstein combined empirical and theoretical 
research to explicate the differences between individual and personal identity and defined the explicit contexts, processes and conditions in society that work to interiorize and exteriorize social relationships and shape the wider institutional and cultural situations that frame identity and so, class and society.

\section{Bernstein and educational research}

Bernstein's (1975) code theory can work well as the theoretical foundation of educational research exploring complex teaching and learning phenomena as not only have his view on the sociology of education been justified by succeeding events in society, but his code theory can illuminate how the school can act as a strong independent force in shaping a student's identity and essentially, their view of the world:

'What the school does, its rituals, its ceremonies, its authority relations, its stratification, its procedures for learning, its incentives, rewards and punishments, its very image of conduct, character and manner, can modify or change the pupil's role as this has been initially shaped by the family. Thus the number of pupils initially involved in a particular role can be modified or changed by the school itself'. (Bernstein, 1975, pp. 48-49 original emphasis included)

He argued that schools are the main place where students shape their own values and intuitive and practical views of the world. Like Bourdieu, (Bourdieu, 1973, 1974, 1979, 1991; Harker, 1990; Wilkes, 1990) Bernstein (1975) proposed that education is the primary social classifier in society. Underlying his theory was his claim that the school acts as the social classifier through what he terms the 'three common message systems' that all schools around the globe have in common: curriculum, pedagogy and assessment. These three message systems work to make education '...an agency of socialization and allocation' $(1975, \mathrm{p}$. 199) and through them, difference is produced and reproduced:

'Formal education knowledge can be considered to be realized through three message systems: curriculum, pedagogy, and evaluation. Curriculum defines what counts as a valid knowledge, pedagogy defines what counts as a valid transmission of knowledge, and evaluation defines what counts as a valid realization of this knowledge...' (p. 85)

He stated that through the three message systems of a school, the dominant cultural group controls, classifies, produces and transmits what knowledge is to be learnt and what values and attitudes are acceptable in that society. According to Bernstein's code theory, students develop values within the culture of the school through contradictory and paradoxical practices - external global market forces and pedagogies are becoming more market-oriented, yet traditional social hierarchies, social values and traditional rituals and practices are being retained, creating oppositional discourses within the school culture.

Bernstein viewed education as ' ...central to the knowledge base of society, groups and individuals. Yet education, like health, is a public institution, central to the production and reproduction of distributive injustices' (Bernstein, 2000 , p. xix). He further stated that 'education can have a crucial role in creating tomorrow's optimism in the context of today's pessimism. But if it is to do this then we must have an analysis of the social biases in education' (p. xix). These biases, he argued, 'lie deep within the very structure of the educational system's processes of transmission and acquisition and their social assumptions'. (p. xix)

Bernstein's social control theory challenges any 'shared' value system. Using his code theory, one can question ways in which dominant value systems within schools work towards interfering with or supporting student learning. It can be used to question ways in which values could or are being reproduced, maintained or produced implicitly by the dominant class and dominant culture of the school. After all, Bernstein argued that '...the expressive order of the school is transmitted... through its ritualization' (1975, p. 61) of different forms, and that schools are highly bureaucratic organizations and '...a major instrument of the division of labor through its control over the occupational fate of its pupils'. (1975, p. 63)

Any project using his recent code theory can well use the message systems (assessment, curriculum and pedagogy) to explore and illuminate the discourses in schools that act as the primary 'social control' agencies or classifiers. In this way, the relationship between power and knowledge and its effects on assessment, pedagogy and curriculum can be illuminated. For now, I will devote some discussion to the concepts of Bernstein's theory from which educational research can draw from.

\subsection{Recontextualising}

'The recontextualising field has a crucial function in creating the fundamental autonomy of education' (Bernstein, 2000, p. 33). The official recontextualising field (ORF) of the school creates or constructs pedagogic discourse through its own order by selectively refocusing, relocating and endorsing all discourses within the school. That is, pedagogy, curriculum and assessment are produced through the ORF and agents within the ORF, such as the 
teacher or school initiatives, practices and rituals. The pedagogic recontextualising field (PRF) refers to the recontextualising field outside of the school that dominates and controls the ORF. This can often be the state curriculum authority or national curriculum standards. The strength of control that the PRF will have over the ORF of any school varies from state to state and country to country, but in schools that report to a national or state curriculum, the social context and construction of pedagogic discourse is to some degree determined by the PRF.

The degree in which the pedagogic discourse is controlled by the ORF and the PRF varies. Pedagogic discourse in an educational organization is constructed by the ORF and to varying degrees by power and control the PRF has over the ORF, but the construction of the pedagogic discourse should be viewed more as a principle than an actual discourse as such. Bernstein argued that it is the principle through which all discourses in the school interrelate with each other for the purpose of teaching and learning.

Basically, when a curriculum moves from one place to the other, it gets recontextualised because it is inevitable that a transformation will take place as it is transferred from the state curriculum authorities, to the school, then to the teacher and then to the student. Ideology shapes this process and then ideology becomes shaped by the student when the student realizes and appropriates the discourse. For the educational researcher, one can use the concepts or principles used in Bernstein's recontextualising theory to explore the recontextualising agents in the school. Using this theory helps one to examine the actual transformation of what the school deems worthy of learning, from the PRF to the ORF, to the teacher, and then from the teacher through to the realization of student learning.

\subsection{Classification and framing}

To achieve this, Bernstein's (1971) concepts of classification and framing can be used as a model to illuminate the effects that different structures of the message systems have on student learning, as Bernstein (Bernstein, 1971) claimed that the interactions, boundaries, timing, place, pacing, selection and organization of elements within these message systems greatly impacts on the school environment. Classification and framing describe two types of knowledge codes that Bernstein argued differed depending upon the ways in which the three message systems are constructed. These concepts form different code modalities of pedagogic practice. For educational researchers, these codes can provide a language which can describe relationships, interactions and pedagogic practice. They can provide a language to analyze and describe how the knowledge that learners develop is relayed, constructed and then realized by the learner (acquirer). It helps researchers discover how the content students learn becomes legitimatized, controlled and formed. Code modalities can be explored at the micro or macro level of any educational organization.

In theory, Bernstein originally introduced the terms classification to illuminate:

'...the means by which power relations are transformed into specialized discourses, and framing is the means where by principles of control are transformed into specialized regulations of interactional discursive practices (pedagogic relations) which attempt to relay a given distribution of power'. (Bernstein, 2000, p. xvii, brackets in original)

It is important to highlight that Bernstein's original intention was not to design these terms from which researchers could use as a framework for distinguishing and describing classroom practice. However, although this was not Bernstein's intention, these concepts can have research relevance independent of its role in his theory. The formulation has an important function in his theory, but one can also draw from these terms for research relevance, as the logic of these concepts provide a language from which classroom practice can be described and as such, they provide a sound basis for analyzing power relations and principles of control within any educational organization.

\subsubsection{Classification}

Fundamentally, the concept of classification is the way in which power relations are constructed into particular discourses. For the purpose of the researcher, it can specifically indicate the degree of boundary maintained between different things in the school:

'Where classification is strong, contents are well insulated from each other by strong boundaries. Where classification is weak, there is reduced insulation between contents, for the boundaries between contents are weak or blurred. Classification thus refers to the degree of boundary maintenance between contents'. (Bernstein, 1971, p. 49; emphasis in original)

Not only can classification refer to the degree of boundary maintained between subject content, but it can also refer to other aspects such as playground areas, assessment strategies, relationships or even the layout of 
classrooms. In a school where subject content is taught in isolation of each other, i.e, Science is clearly distinct to English, Mathematics is clearly distinct to other subject areas, there is a strong degree of boundary between each subject, and so, the classification can be described as strong.

Classification can also be referred to within subject areas. For example, classification can be described as weak where a teacher focuses on different reading skills at the same time. Strong classification rules may occur in the class where a teacher assesses different reading skills as separate entities. In this way, classification can vary within the context of one lesson. You could have strong classification over the subject content taught in the class, but weak classification over the teacher that delivers the content, where teachers may rotate classrooms to teach within that subject. Playgrounds may be strongly classified in a school where certain year levels are each designated their own play area. In some schools, students are able to mingle anywhere in the school regardless of age. In these cases, the playground area can be described as weakly classified.

In a school, Bernstein claimed that power relations were essentially translated into principles of classification, which basically determined the degree of boundary between which things are kept apart and the degree in which they are kept together. By analyzing the degree of boundary between things in a school, the educational researcher can start to explore ways in which power is being transmitted through the three message systems.

\subsubsection{Framing}

Fundamentally, the concept of frame is used to refer to the ways in which principles of control are conveyed through particular regulations of interactional relationships and discursive practices, which attempt to construct and distribute power. In the school, it can be used '...to refer to the strength of the boundary between what may be transmitted and what may not be transmitted in the pedagogic relationships'. (Walford, 1995, p. 192; my emphasis) It specifically refers to 'the degree of control teacher and pupil poses over the section, organization, pacing, and timing of knowledge transmitted and received in the pedagogical relationship'. (Bernstein, 1971, p. 50)

For the educational researcher, one can draw from his concept of framing to illuminate the power relations behind communication in pedagogic relationships. It can provide a language of description from which we can understand what learners have access to, and what they do not. It refers to how meanings in the classroom are constructed, made public and the nature of the social relationships behind putting it together. Using an example of classroom use, it may refer to the relationship between the teacher and the student and the degree of autonomy each person has in that relationship in regards to what the learner has access to, when content is taught, how that content is prioritized and the physiological and environmental factors in which the learning takes place. (Bernstein, 2000)

It also can refer to the timing of curriculum content in the sense of what content is taught when, and what takes priority over the other. Analyzing the strength of framing in an educational organization can help illuminate the power particular agencies have over what, when and how knowledge is learnt. Through the strength of framing, students learn what questions can be asked and when, and what is more valuable than the other. For example, in a classroom where students are only allowed to speak at certain times, the framing could be described as strong. However, the same classroom may have weak framing in regards to the pacing of subject content such as when students exert autonomy over when they can complete tasks. Bernstein claimed: 'The student learns that only certain kinds of questions can be put at any one time, and the teacher learns to provide a certain kind of answer. Thus as frame strength over pacing changes, so does answering and questioning behavior'. (Bernstein, 1975, p. 9)

It is in this way that the educational researcher can start to understand ways in which the curriculum is primarily socially constructed, through the choices leaders and teachers have when constructing the curriculum - some subjects being given special status over others: '...there is nothing intrinsic about how educational time is used, or the status of the various contents or the relation between the contents'. (Bernstein, 1975, p. 80)

\subsection{Curriculum Types}

Bernstein distinguished between two different types of curriculums that result from the variations in the framing and classification - open and closed. He termed the closed curriculum (a strongly classified curriculum) a collection type - '...here, the learner has to collect a group of favored contents in order to satisfy some criteria of evaluation' (p. 87) and all subjects are taught in isolation of each other with strong boundaries separating each subject content. In an open curriculum, what he termed an integrated curriculum type (a weakly classified curriculum), the subjects are not isolated from each other and the boundaries between them are broken down, relationships being drawn between them. 
Bernstein's concepts of classification and framing, which '...is at the heart of Bernstein's theory of curriculum' (Sadovnik, 2001, p. 14) can help one to understand the evaluation and curriculum of any educational organization. Using this framework, the educational researcher can start to understand relationships between different variations of classification and framing, the evolution of knowledge and some of the consequences of these variations on different groups.

\section{Conclusion}

For examples of researchers using Bernstein's theory as a theoretical foundation for educational research, refer to research projects undertaken by Hasan and her colleagues (Hasan, 1991, 1992, 1993), Cause (2009) and Wylie (2007, 2008). Bernstein's most recent development of his code theory (see Bernstein, 2000) can help the educational researcher to analyze the social processes within educational organizations. It can then offer a language of description from which to understand and describe the construction (framing and classification) of the three message systems. Analyzing the strength of boundaries maintained in a school (classification) and analyzing the range of options teachers or students have, or the control they have over what is and is not taught (strength of framing) can help researchers better understand the ways in which knowledge is relayed and formed.

Essentially, using Bernstein's theory allows power relationships to be brought into the analysis so that the concepts that illuminate significant influences in the shaping of knowledge can be examined, distinguishing rather than dichotomizing different transmission structures. At a micro level, it helps to bring into analysis the ways in which the teacher influences student learning through the control each teacher possesses over what $i s$ and is not transmitted through pedagogy, assessment and curriculum. At the macro level, it helps to illuminate the influence outside agencies have on what, how and when content is transmitted.

Any project using his recent code theory can well use the message systems (assessment, curriculum and pedagogy) to explore and illuminate discourses in schools that act as the primary 'social control' agencies or classifiers. Researchers can draw from the most recent development of his code theory to analyze and provide a clear language of description to illuminate ways in which power and control operate within and between educational organizations. If more educational researchers start to use his theory, the relationships between power and knowledge and its effects on ultimately classifying and distributing power relations in wider society may start to be more clearly illuminated.

\section{References}

Atkinson, P. (2001). The Legacy of Basil Bernstein. In P. Aggleton, J. Brannen, A. Brown, L. Chisholm, J. Mace \& S. Power (Eds.), A Tribute to Basil Bernstein: 1924-2000 (pp. 35-38). London: Institute of Education.

Bernstein, B. (1971). On the Classification and Framing of Educational Knowledge. In M. Young (Ed.), Knowledge and Control (pp. 47-69). London: Collier-Macmillan.

Bernstein, B. (1975). Towards a Theory of Educational Transmissions (Vol. 3). London: Routledge \& Kegan Paul.

Bernstein, B. (1990). The Structuring of Pedagogic Discourse (Vol. 4). London: Routledge \& Keegan Paul.

Bernstein, B. (2000). Pedagogy, Symbolic Control and Identity. Oxford, England: Rowman \& Littlefield Publishers, Inc.

Bourdieu, P. (1973). Cultural reproduction and social reproduction. In R. Brown (Ed.), Knowledge, Education and Social Change. London: Tavistock.

Bourdieu, P. (1974). The school as a conservative force: scholastic and cultural inequalities. In J. Eggleston (Ed.), Contemporary Research in the Sociology of Education. London: Methuen.

Bourdieu, P. (1979). Symbolic power. Critique of Anthropology, 4, 77-85.

Bourdieu, P. (1991). Epilogue: On the possibility of a field of world sociology. In P. Bourdieu \& J. Coleman (Eds.), Social Theory for a Changing Society. Boulder: Westview Press.

Cause, L. (2009). International-mindedness and social control. Asian Social Science, 5(9).

Dickinson, H., \& Erben, M. (1995). Bernstein and Ricoeur: Contours for the Social Understanding of Narratives and Selves. In P. Atkinson, B. Davies \& S. Delamont (Eds.), Discourse and Reproduction: Essays in Honour of Basil Bernstein (pp. 253-268). New Jersey: Hampton Press, Incorporated.

Gibson. (1977). Bernstein's classification \& framing: a critique. Higher Educational Review, 9, 23-45.

Harker, R. (1990). Bourdieu: Education and Reproduction. In R. Harker, C. Maher \& C. Wilkes (Eds.), An 
Introduction to the Work of Pierre Bourdieu: The Practice of Theory (pp. 86-108). London: Macmillan Press Limited.

Hasan, R. (1991). Questions as a mode of learning in everyday talk. In M. McCausland (Ed.), Language Education: Interaction and Development. Launceston: University of Tasmania.

Hasan, R. (1992). Meaning in sociolinguistic theory. In K. Bolton \& H. Kwok (Eds.), Sociolinguistics Today: International Perspectives. London and New York: Routledge.

Hasan, R. (1993). Contexts for Meaning. In J. E. Alatis (Ed.), Language, Communication and Social Meaning. Washington, DC: Georgetown University Press.

Jenks, C. (1995). Decoding Childhood. In P. Atkinson, B. Davies \& S. Delamont (Eds.), Discourse and Reproduction: Essays in Honour of Basil Bernstein (pp. 173-190). New Jersey: Hampton Press, Incorporated.

King, R. (1976). Bernstein's sociology of the school: some propositions tested. British Journal of Sociology, 27, 430-443.

King, R. (1981). Bernstein's sociology of the school. British Journal of Sociology, 32, 259-265.

Pring, R. (1975). Bernstein's classification and framing of knowledge. Scottish Educational Studies, 7, 67-74.

Sadovnik, A. R. (2001). Basil Bernstein (1924-2000): sociologist, mentor and friend. In P. Aggleton, J. Brannen, A. Brown, L. Chisholm, J. Mace \& S. Power (Eds.), A Tribute to Basil Bernstein: 1924-2000. London: Institute of Education.

Walford, G. (1994). Classification and framing in English public boarding schools. In P. Atkinson, B. Davies \& S. Delamont (Eds.), Discourse and Reproduction. New Jersey: Hampton Press.

Walford, G. (1995). Classification and framing in English public boarding schools. In P. Atkinson, B. Davies \& S. Delamont (Eds.), Discourse and Reproduction: Essays in Honor of Basil Bernstein (pp. 191-208). Cresskill, New Jersey: Hampton Press.

Wilkes, C. (1990). Bourdieu's Class. In R. Harker, C. Maher \& C. Wilkes (Eds.), An Introduction to the Work of Bourdieu: The Practice of Theory (pp. 109-132). London: Macmillan.

Wylie, M. (2007). What is International about International Education? Geelong: Deakin University.

Wylie, M. (2008). Internationalizing curriculum: framing theory and practice in international schools. Journal of Research in International Education, 7(1), 5-19. 